\title{
Partial evulsion of optic nerve
}

\section{Fluorescein angiographic study}

\author{
J. C. DEAN HART AND S. F. J. PILLEY \\ Western Ophthalmic Hospital, London
}

Evulsion of the optic nerve is a rare complication of trauma though well recorded in the literature (Lang, I90 I Gruber, I959; Hughes, 1962).

Concurrent haemorrhage into the vitreous often delays diagnosis so that when ophthalmoscopy is possible the optic disc is masked by glial tissue extending into the vitreous. Persistence of these opacities may permit accurate diagnosis only after pathological examination (Lister, 1924).

Spizziri (1964) photographed an evulsion of the optic nerve 12 days after the initial injury and Rosen, Ashworth, and Järpe (1969), showed a picture of glial proliferation after partial optic nerve evulsion.

The present paper reports a case of partial evulsion of the optic nerve in which fluorescein studies were performed 40 hours after the injury.

This is the first study of its kind in which changes in vascular flow are reported.

\section{Case report}

A 22-year-old male student was struck by a hand on the left eye, whilst playing water-polo. He noted immediate loss of vision in the left eye, and was examined 45 minutes after the injury.

\section{Examination}

RIGHT EYE

Normal in all respects with a visual acuity of $6 / 6$, a full visual field, and an intraocular pressure of I $\mathrm{mm}$. Hg.

\section{LEFT EYE}

The visual acuity was 6/6o. Although the conjunctiva was injected and a small subconjunctival haemorrhage had occurred over the insertion of the lateral rectus, no break in the conjunctiva could be found. The anterior chamber was of normal depth and clear, and the pupil was semidilated, reacting only sluggishly to light.

The lens appeared undamaged and not displaced. An excellent view of the fundus could be obtained and the following features were noted. Although there was extensive retinal oedema at the posterior pole, the major retinal vessels appeared normal but were obscured by a preretinal haemorrhage nasal to the disc. The disc had a deep cleft superiorly extending circumferentially from 10 to 3 o'clock, which widened on elevation of the eye and narrowed on depression, suggesting that the globe hinged on the portion of the optic nerve that remained attached inferiorly. 
The retinal periphery was unremarkable. The intraocular pressure was $7 \mathrm{~mm}$. Hg. The visual field showed marked field loss with retention of a small area of field above and temporal to fixation (Fig. I object size 1o $\mathrm{mm}$. white).

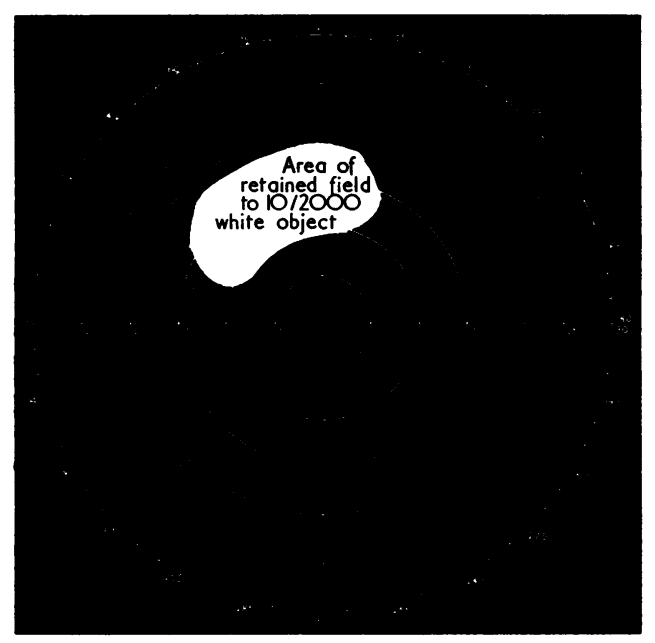

FIG. I Preservation of small field extending upwards from region of disc to $10 / 2000$ white object

\section{Radiology}

No fractures of the orbital walls were seen.

\section{Diagnosis}

Partial evulsion of the optic nerve was diagnosed and the patient was admitted to hospital.

\section{Subsequent course}

One week after admission the patient was discharged, and 2 days later an extensive vitreous haemorrhage occurred preventing further fluorescein angiography.

Examination 6 weeks later showed the retina, at the posterior pole, to be completely obscured by an organizing vitreous haemorrhage. The visual acuity was reduced to perception of light. The intraocular pressure was $12 \mathrm{~mm}$. Hg.

\section{Fluorescein angiography}

When this was performed 40 hours after the injury, a further preretinal haemorrhage had occurred nasal to the disc and fronds of haemorrhage were noted tracking inferiorly. The disc remained clearly visible (Fig. 2).

There was prompt arterial filling at 10 seconds in all quadrants after injection of the dye into the antecubital vein. Venous filling of the inferior vessels occurred ( 14 seconds, Fig. 3 ) but was delayed in the superior vessels (22 seconds Fig. 4). The small vessels on the superior half of the disc did not fill with dye and the fluorescein leaked from the outer edge of the defect in the optic nerve. The dye persisted in the superior retinal veins after the inferior veins had emptied.

\section{Conclusion}

The retinal arteries and inferior retinal veins appeared unaffected by the trauma. The superior retinal veins were partially occluded and the small vessels on the surface of the disc were not patent as a result of the injury. 

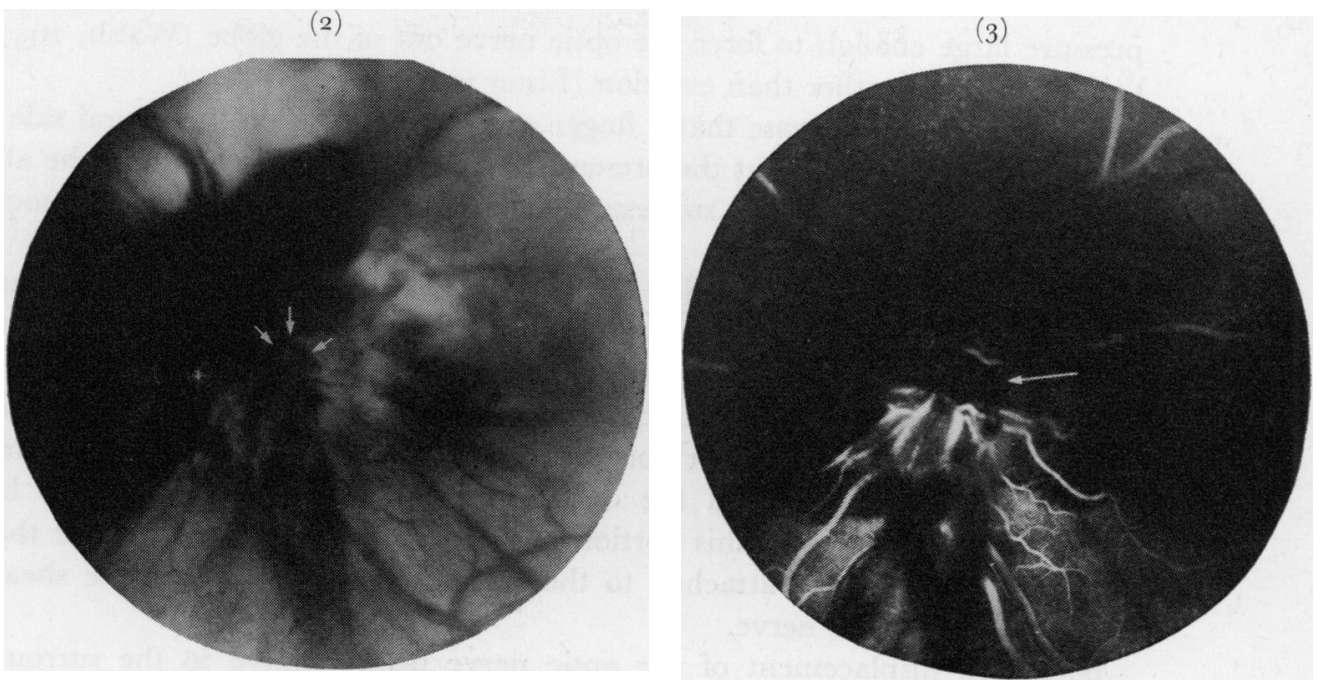

FIG. 2 Copy of colour. Photograph of left fundus showing outline of partial evulsion (arrows). A vitreous haemorrhoge is present superonasally. Areas of retinal oedema are seen temporal to the disc

FIG. 3 Fluorescein angiography arteriovenous phase (1 4 seconds after injection). Normal arteriovenous flow below and only arterial filling above. Note absence of dye in vessels on superior half of disc indicated by arrow

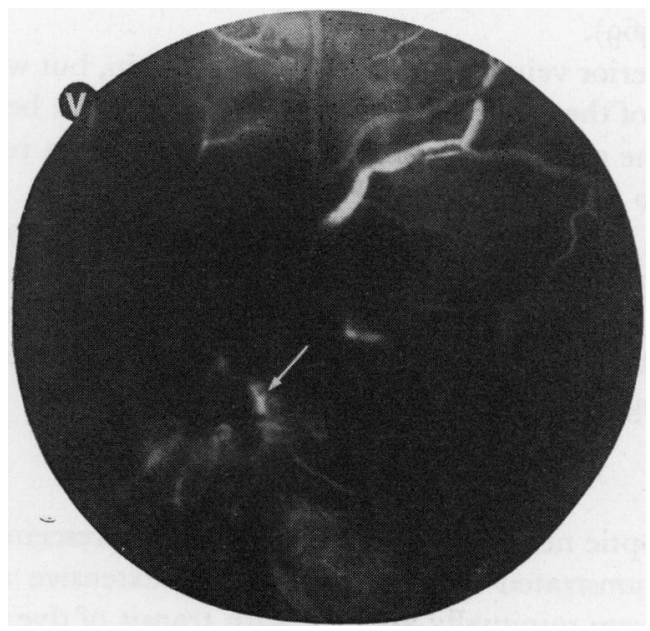

FIG. 4 Fluorescein angiography late venous phase (22 seconds after injection). Delayed venous filling of superior veins. Leakage of dye is occurring on outer margin of defect in optic nerve (arrow)

\section{V - Superior nasal vein.}

\section{Comment}

Several theories have been postulated as to the mechanism involved in evulsion of the optic nerve. When the integrity of the globe is maintained, evulsion most commonly occurs when a stick or spike enters the orbit, rotates, and pushes the globe forwards, so stretching the optic nerve and pulling it out of the scleral ring (Stanton-Cook, 1953). Propulsion of the globe forwards may also occur through blast from high velocity missiles passing through the posterior portion of the orbit or pterygo-maxillary fissure (Lagrange, I9 I 7).

Less commonly, blunt trauma to the front of the globe may produce a rise in intraocular 
pressure large enough to force the optic nerve out of the globe (Walsh, 1957). In effect this is expulsion rather than evulsion (Lister and Hine, 1919).

It is possible in our case that a finger entered the orbit on the lateral side and that the globe rotated forwards, but the presence of an intact conjunctiva and the absence of any evidence of orbital trauma suggests that a sudden massive rise in intraocular pressure caused the injury.

Histological reports of evulsion of the optic nerve clearly demonstrate that the rupture of the nerve occurs at the margin of the disc in the same plane as the termination of Bruch's membrane, i.e. at a junctional area. Löwenstein (1943) thought that rupture of the optic nerve occurred at the cribriform plate because of the anatomical weakness of that region. The posterior portion of the lamina cribrosa is only a third as thick as the surrounding sclera, and the optic nerve fibres are not supported by myelin or connective tissue septa in this portion of the nerve. He also noted that the optic nerve sheath usually remains attached to the globe and suggested that the sheath was more elastic than the optic nerve.

Backward displacement of the optic nerve head relative to the surrounding ocular structures produces shearing stresses which act on the blood vessels crossing the disc head. The small vessels with thin walls are most likely to be implicated. Fluorescein angiography shows that there is an absence of capillary filling on the superior half of the disc central to the cleft in the optic nerve, and that leakage of dye occurs from the outer margin of the defect, thus providing factual evidence that the disc head does not receive a blood supply from the retinal vessels within the margins of the disc but probably from the choroidal circulation (Hayreh, 1969).

The partial occlusion of the superior veins is more difficult to explain, but with backward displacement of the superior half of the optic nerve these vessels may have become sharply angulated in their passage over the outer edge of the defect, resulting in a reduced lumen and hence increasing resistance to flow.

The normal fluorescein flow in the retinal arteries and inferior retinal veins and slightly reduced transit in the superior veins indicates a remarkable ability of these vessels to stretch. The field loss is therefore entirely due to the rupture of nerve axons at the optic disc. Fluorescein angiography, however, demonstrates that the blood supply of the disc is centripetal rather than centrifugal.

\section{Summary}

A case of partial evulsion of the optic nerve is presented in which fluorescein angiography was performed. The study demonstrated that, in spite of the extensive nature of the injury, the major retinal vessels were minimally affected with transit of dye through both arteries and veins. The only vessels significantly affected were small vessels in the region of the disc. The field loss was due to rupture of nerve axons at the margin of the disc.

We are indebted to Mr. John Wright for his help in the preparation of the paper and for permitting us to report on his patient, to Miss $\mathrm{K}$. Phillips for the preparation of the illustrations, and to Miss J. Lace for secretarial services.

\section{References}

GRUBER, E. (1959) Amer. F. Ophthal., 48, 528

HAYREH, s. s. (1969) Brit. F. Ophthal., 53, 721

HUGHes, B. (1962) Bull. Johns Hopk. Hosp., 111, 98 
LAGRANGE, F. (I9I7) “Les fractures de l'orbite par les projectiles de guerre". Masson, Paris LANG, W. (IgOI) Trans. ophthal. Soc. U.K., 21, 98

LISTER, w. (1924) Brit. F. Ophthal., 8, 305

- and HINE, M. L. (1919) Trans. ophthal. Soc. U.K., 39, 196

LÖWENSTEIn, A. (I943) Brit. J. Ophthal., 27, 208

ROSEN, E. S., ASHWORTH, B., and JÄRPE, s. (1969) "Fluorescence Photography of the Eye. A

Manual of Clinical Ocular Fundus Pathology". Butterworths, London

SPIzziri, L. J. (1964) Amer. F. Ophthal., 58, 1056

STANTON-COOK, L. (1953) Brit. F. Ophthal., 37, 188

WALSH, F. (1957) "Clinical Neuro-Ophthalmology", 2nd ed., p. 3 r. Williams and Wilkins,

Baltimore 